\title{
STABILIZATION OF SUBGRADE SOIL USING CALCIUM LIGNOSULFONATE AND GRANITE DUST- A REVIEW
}

\author{
N. Manikyala Rao ${ }^{1}$, B.P.R.V.S Priyatham ${ }^{2}$ \\ ${ }^{I}$ PG Scholar, Transportation Engineering, GMR Institute of Technology-Rajam, Andhra Pradesh, India. \\ ${ }^{2}$ Asst. Professor, Dept. of Civil Engineering, GMR Institute of Technology-Rajam, Andhra Pradesh, India.
}

Article DOI: https://doi.org/10.36713/epra8430

DOI No: 10.36713/epra8430

\begin{abstract}
ABSTARCT
India is a geographically diverse country with varied soil types in different places. As a result, stabilising techniques are employed to enhance those regions with low bearing capacity. Soil strength is improved using both mechanical and chemical stabilising techniques. In the mechanical approach, mechanical energy is employed (rollers, plate compactors, tempers, etc., depending on the choice or type of the soil) to enhance soil characteristics by compaction. Chemical Soil Stabilization is a chemical approach that involves blending and combining chemical additions to improve the soil's engineering qualities. Chemical substances such as calcium lignosulfonate, granite dust, cement, and fly ash were added in. Although calcium lignosulfonate may stabilise a wide variety of soil types, it works best in soft soils and clay soils with moderate to medium flexibility. Granite dust is primarily used in clay soils with a lot of flexibility.
\end{abstract}

KEY WORDS: Calcium lignosulfonate, Granite dust, soil, stabilization, subgrade

\section{INTRODUCTION}

Natural soil is extremely beneficial for agriculture as well as engineering. Soil serves as a foundation material for buildings, highways, railways, airports, and harbors, among other things. Strength varies depending on the kind of soil; if the soil is too weak for the construction at hand, stabilising techniques must be used to enhance the soil's strength. Select the right type and number of stabilisers before beginning soil stabilisation. To verify that the planned aims of soil stabilisation are met, evaluate the material characteristics and field performance. The objectives of soil stabilisation are to dry out the building site and offer a working platform, reduce soil plasticity index (PI), increase soil density, minimise shrink or swell features, improve soil strength and stability, reduce moisture susceptibility, and use local resources. With variations in moisture content, many clayey soils have the capacity to shrink and swell. The volume changes in the soil as a result can be detrimental to any buildings erected on it. To regulate this shrink/swell tendency and hence minimise possible harm, a multitude of stabilising techniques have been utilised. For many years, soil stabilisation has been the focus of study in this field, with additions such as calcium lignosulfonate, granite dust, cement, lime, fly ash, silica fume, and calcium chloride being used. Calcium lignosulfonate and granite dust are the most often utilised admixtures because they provide chemical and cementing products that bind the clay particles, reducing plasticity, shrinkage, and swelling while also improving strength. The main goal of this study was to evaluate calcium lignosulfonate and granite dust as subgrade soil stabilising agents in the building of pavements. Preliminary research and monitoring are part of the study. 


\section{EPRA International Journal of Research and Development (IJRD)}

Volume: 6 | Issue: 9 | September 2021
- Peer Reviewed Journal

\subsection{Materials}

Calcium Lignosulfonate:

Lignosulfonate is a non-toxic, non-corrosive waste product of the paper and wood processing industries. The lignin is removed from the cellulose in the industrial process, and because lignin is water insoluble, it is transformed to lignosulfonate by a chemical process known as sulfonation. Lignosulfonates are commercially accessible as sodium and calcium salts and have been utilised in a wide range of applications by industry. Calcium lignosulfonate is a light-yellow-brown amorphous powder made from softwood sulfite pulping. Carbon (C), oxygen (O), sulphur ( $\mathrm{S}$ ), and sodium ( $\mathrm{Na}$ ) are all present in this substance $(\mathrm{Na})$. Lignosulfonate is a lowcost, simple-to-use substance that can be effective quickly. The functional groups $\mathrm{OH}$, benzene ring, $\mathrm{C}-\mathrm{H}$ stretching group, C-O bond primary alcoholic group, $\mathrm{C}-\mathrm{O}$ bond secondary alcoholic group, $\mathrm{C}-\mathrm{O}-\mathrm{C}$ stretching -OCH3 group, and $\mathrm{S}=\mathrm{O}$ stretching sulfonate group are all present in the lignosulfonate molecular structure.

\section{Granite Dust}

Granite dust is an industrial by product formed after the primary and secondary crushing of aggregates from aggregate crushing units. At an average a particular aggregate from a typical rock produces roughly around 400 - 500,000 tons every year. A Crusher unit produces an unused material around 20$25 \%$ of its production. In India, annually about 200 million tons of quarry by-products are being produced. Granite dust being discarded in a huge amount is creating a financial and ecological expense to the quarrying cycle. Bulk utilization of this industry by product is necessary to avoid geo environmental problems health hazards related to its disposal. The granite dust can also avoid detrimental effects on the environment due to the excessive mining of river sand. Kallchef 1977 was the first to use the granite dust as a partial replacement of sand in Plain cement concrete. His work concluded that the behaviour of PCC was well acceptable at some gradations of granite dust. Granite dust can be used as a substitute for sand to improve the geotechnical properties of soil. These are well accepted as well as cost effective ground improvement technique for weak soil deposits.

\section{LITERATURE REVIEW}

Rama varaprasad et al (2020) the description of expansive soils treated with Lignosulfonate was investigated. Amaravati and Vijayawada, both in the state of Andhra Pradesh, were the locations where soil samples were obtained for this study. The percentages were taken at completely distinct rates of $0.5,1,2$, and 4 percent. Tests in the laboratory were performed on

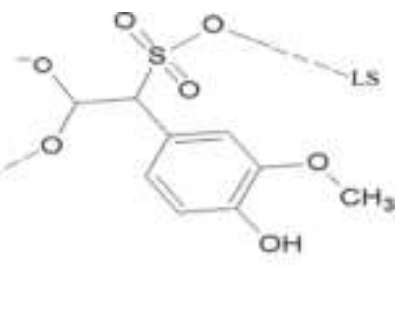

re of CLS

the atterberg limits, standard compaction, CBR, and UCS parameters. When Lignosulfonate is added to the soil, the UCS of the soil increases.

Geethu Vijayan et al (2019) the use of Lignosulfonate in the stabilization of clayey soil was researched and tested. Clayey soils will be considered stable for this evaluation of the literature. There are several tests that are carried out, including the standard compaction test, the unconfined compressive strength test, the C.B.R. limit, and the Atterberg limit. In conjunction with the addition of Lignosulfonate, the maximum wet density will be reduced while the maximum dry density will be increased, as previously stated. The addition of Lignosulfonate increases the shear strength characteristics of the material, while the liquid limit decreases and the plastic limit increases with the presence of the compound.

Nauman Ijaz et al (January 2020) Integrating lignosulphonate and hydrated lime for the amelioration of expansive soil were the subjects of this research. In this article, lignosulphonate (LS) is used in conjunction with hydrated lime to stabilize the soil (LM). A comprehensive experimental investigation of the suggested composite binary admixture was carried out (CBA) On the basis of the plasticity index, the optimal binary admixture (OBA) was determined. The different percentages of taken are 0.4 percent, 0.875 percent, and 2 percent, and the different percentages of lime are 2.625 percent, 3.82 percent, 5 percent, 6.5 percent, and 9 percent. The different percentages of taken are 0.4 percent, 0.875 percent, and 2 percent. In accordance with test results, several geotechnical parameters, including plasticity, swelling and shrinkage, strength 


\section{SJIF Impact Factor 2021: 8.013| ISI I.F.Value:1.241| Journal DOI: 10.36713/epra2016 ISSN: 2455-7838(Online) EPRA International Journal of Research and Development (IJRD)}

and hydraulic conductivity, were investigated and evaluated. Addition lowers the amount of lime required for widespread soil stabilization while also providing a long-term solution for reducing industrial waste production and disposal. LS and LM were used to remediate expansive soil in the laboratory, and a wide range of geotechnical characteristics were studied. 2.625 percent lime in combination with 0.875 percent alumina was determined to be effective based on the plasticity index and swelling behavior of the treated expansive soil.

Yizhou Li et al (2020) investigated the In Situ Evaluation of Using for Subgrade Stabilization in a laboratory environment. There have been a few laboratory studies on soil stabilization with lignosulfonate that have been done. Dilute ammoniumbased spray was used on this area to improve the strength and longevity of a gravel road subgrade, which was previously weak. The tests were performed before, one week after, and six months after the building. The light-weight deflect meter (LWD) tests and the dynamic cone-penetration (DCP) testing were performed before, after, and after the construction. The stiffness of the subgrade reduced after one week of construction due to the excessive amount of water used in the dilution, and it increased after six months of construction as a result of seasonal climatic changes and vehicle loads. The strength of the subgrade was influenced not only by compaction effort and constant vehicle loads, but also by seasonal variations in compressive strength, which were observed.

Buddhism Indraratna et al (2012) Lignosulfonatetreated soils were investigated for their chemical and mineralogical behavior. The findings of Unconfined Compressive Strength tests on clay soils that have been stabilized with lignosulfonate are presented in this study (UCS). Laboratory investigations have revealed that lignosulfonate can increase the stiffness of soils when applied in small amounts. The impact of clay minerals on the stability of Lignosulfonate is examined using Fourier Transform Infrared (FTIR) Spectroscopy and Electrical Conductivity measurements, among other techniques (EC). Lignosulfonate has the potential to be used in clay soil stabilization since it is an environmentally acceptable additive that is also effective. The findings of the unconfined compression tests indicate that the shear strength parameters of lignosulfonate treated soils, such as the ultimate strength and stiffness, improve with the amount of lignosulfonate used and the length of curing time used.

Geethu Vijayan et al (April 2019) A study was conducted to determine the effects of lignosulfonate on the compaction and strength characteristics of clayey soil. Improved the load-bearing capability of a subgrade for the purpose of supporting pavements and foundations by increasing the shear strength characteristics of the soil. When it comes to subgrade materials, stabilization may be applied to a wide range of materials, from expansive clays to granular materials. Lignosulfonate is a soil stabilizing chemical that is particularly effective in soft soils. The compaction characteristics and shear strength qualities of several materials were investigated in this literature. It is possible to employ different percentages of lignosulfonate (e.g., 1, 2, 3, 4, 5, 6 percent), as well as compaction and unconfined compressive strength measurements. Because of the addition of lignosulfonate, the OMC drops and the MDD increases. Because of the inclusion of lignosulfonate, the shear strength will be increased.

Dr. A. U. Ravi Shankar et al (December 2017) The Experimental Investigation of Lateritic Soil treated with Calcium Lignosulfonate was the subject of this research. Improvements in the strength and engineering characteristics of soil can be achieved by soil stabilization. Lateritic soil is being examined to see whether its characteristics improve when it is treated with Calcium Lignosulfonate at concentrations ranging from 0.5 percent to 2 percent of the soil's total calcium content. Proctor densities of both Light and Heavy proctor density were used to compress lateritic soil and stabilized soils. A variety of soil tests, including unconfined compressive strength (UCS), California Bearing Ratio (CBR), and durability tests, are used to stabilize the soil. This research revealed that raising the amount of Calcium Lignosulfonate resulted in a greater maximum dry density and a lower optimal moisture content than previously thought. Higher UCS values and a minor rise in CBR values were seen in the lateritic soil when different percentages of Calcium Lignosulfonate were added for the standard proctor test and 2 percent Calcium Lignosulfonate was added for the modified proctor test, respectively, in the lateritic soil. Following the addition of CLS, the maximum dry density increases while the maximum moisture content decreases.

Dennis Pere Amazigh et al (April 2016) The swelling behavior of expansive soil treated with lignosulfonate was investigated. The results of using lignosulfonate to reduce the swelling of expansive soil are presented in this study. Untreated and LS-treated samples are tested for swelling. When the findings were compared to the same cement-treated soil samples, it was discovered that Lignosulfonate might be a cost-effective and ecologically friendly alternative to conventional alkaline additions. Swelling and durability tests, as well 


\section{SJIF Impact Factor 2021: 8.013| ISI I.F.Value:1.241| Journal DOI: 10.36713/epra2016 ISSN: 2455-7838(Online) EPRA International Journal of Research and Development (IJRD)}

as microstructural analyses, were undertaken to assess the possible usefulness of LS in stabilising remoulded expansive soil. According to the findings, the ideal LS concentration for improving percentage swelling is $2 \%$ by dry weight of the soil, and $\mathrm{pH}$ does not change after LS addition.

Mariano T. Fernandez et al (November 2020) Calcium lignosulfonate's performance as a clay stabiliser was investigated. A natural smectite clay was mixed with calcium lignosulfonate in this experiment. 3 and 5 percent of CLS were used to stabilise clay. Calcium lignosulfonate's effect on the physical characteristics of clay, Atterberg limits, Cation Exchange Capacity, and Specific Surface Area was investigated. A series of experiments were conducted to characterise the physical, hydraulic, and mechanical characteristics of three mixtures: natural clay, natural clay 3 percent, and calcium lignosulfonate 5 percent. Physical and technical characteristics were altered as a result of the study. Clay's liquid and shrinkage limitations were both raised once CLS was added. When the specific surface (Se) and cation exchange capacity (CEC) of CLS treated and untreated samples were compared, a significant decrease in Se and CEC was seen as the CLS percentages increased. Clay's UCS was enhanced by adding calcium lignosulfonate.

Dennis Pere Amazigh et al (November 2017) In expansive soils, researchers explored the mechanisms of soil stabilisation utilising lignosulfonate admixture. The techniques by which remoulded expansive soil was remoulded expansive soil were investigated and determined using a non-traditional admixture (lignosulfonate) (LS). X-ray Diffraction, a Scanning Electron Microscope coupled with an Energy Dispersive Spectroscopy, Fourier Transform Infrared, Computed Tomography, Nuclear Magnetic Resonance, Cation Exchange Capacity, and the role of Specific Surface Area, among other techniques, were used to investigate untreated and LS treated samples of expansive soil. To see if there were any variations in the physical or chemical properties of treated and untreated soil samples. The amount of water absorbed by the expanding clay minerals during the experiment was proportionate to the percent swell, according to the results. Aside from that, even a small amount of an organic component like LS may have a big influence on how much moisture is available in a big soil. Researchers were able to figure out how LS, a nontraditional waste by-product, stabilised an enlarged silty clay that had been remoulded by completing a series of micro-characterization studies. The physical and chemical properties of the soil following LS treatment were compared to those of untreated samples to see if the admixture caused any changes. The addition of LS in the remoulded soil had a greater impact on the expansive clay minerals in the soil samples and a smaller impact on the non-expanding clay minerals.

Bahram Ta'negonbadiet at al (September 2018) Long-term physical and geotechnical properties of lignosulfonate-stabilized clay were investigated. The stability of stabilised and LS-stabilized clays was evaluated in this work using direct shear testing. The findings of direct shear and unconsolidated-undrained triaxial tests were also subjected to wet and dry cycles, with the results compared as a result. The LS system's stability increased peak shear stress while decreasing volumetric strain. The brittleness index of the unteated and CLS untreated samples dropped as the amount of effective normal stress rose, owing to the changed ductility of the soil caused by the LS-stabilization. Stabilized soil strength parameters such as stabilised soil, cohesion, and internal friction angle decreased as the amount of compaction moisture content in the sample increased, according to the results of direct shear tests; however, this reduction in the strength parameters of direct shear samples was less than that seen in the UCS test. When the number of wetting and drying cycles in the direct shear tests is increased, the volume and peak shear stress of the stabilised and stabilised samples decrease.

Guoyu Li et al (2019) the engineering characteristics of loess stabilized using a form of eco-material known as calcium lignosulfonate were investigated. Chemical stabilization of roads and embankments is a critical part of road and embankment construction. Chemical reaction is used to solidify the soil partical and increase its strength. Loess enhancement is achieved by the use of calcium lignosulfonate, which is a form of ecomaterial. The engineering characteristics of stabilized loess, such as Atterberg limits, Standard compaction test, and unconfined compressive strength, were determined based on experimental findings. The findings indicate that calcium lignosulfonate can enhance the Atterberg limits while decreasing compressive strength. The OMC is decreasing, whereas the MDD is increasing.

R. Tirumala et al (2017) It was studied the stability of black cotton soil that had been damaged by granite waste and quarry dust. Attempts to stabilise soil polluted by granite waste and quarry debris were made over the course of this project. According to the manufacturer's instructions, the experimental work was carried out utilising $10 \%, 15 \%$, and $20 \%$ Granite waste and Quarry soil content. The results of the experimental investigation were based solely on percentage changes 


\section{SJIF Impact Factor 2021: 8.013| ISI I.F.Value:1.241| Journal DOI: 10.36713/epra2016 ISSN: 2455-7838(Online) EPRA International Journal of Research and Development (IJRD)}

in Granite waste and Quarry dirt content in soil throughout testing for soil Liquid limit, O.M.C., M-DD, Bulk density, Dry density, and Grain Size Analysis. The specific gravity of Black cotton soil increased as a result of the addition of quarry dirt and granite waste, and it was observed that the liquid limit decreased from $21 \%$ to $17 \%$ with the addition of quarry dirt and granite waste from $0 \%$ to $20 \%$. The unconfined compressive strength of Black cotton soil improved after 20\% quarry dirt and granite rubble were added to it. When different quantitative relationships of quarry dirt and granite waste are added to black cotton soil, the maximum dry density stabilises while the maximum moisture content decreases.

İsmail Zorluer et al (2017) the use of fly ash and granite mud for soil stabilization was investigated. A series of laboratory experiments were carried out on granular soil samples that had been amended with fly ash and granite mud throughout this research. It took many days to prepare the specimens using granular soil and fly ash-granite mixtures in a variety of various ratios. They were treated with standard Proctor compaction energy and then cured for 1, 7, 28 and 56 days, respectively. Unconfined compressive experiments were carried out to determine the influence of fly ash-granite mud on granular soil strength after curing was completed. The C.B.R. test was carried out on samples that contained additional ingredients. The addition of fly ash-granite mud increased the soil's strength by a factor of two. Therefore, fly ash-granite mud is frequently used in conjunction with granular soil to increase its strength.

Preethi et al (2018) It was studied if granite debris might be used to stabilise black cotton soil. Granite debris is utilised to elevate the height of the soil. Experimental research was conducted utilising readily accessible expansive soil that had been combined with granite rubble to explore this feature. When expansive soil is combined with totally various percentages of granite waste, it changes its index and engineering features, such as liquid limit, plastic limit, plasticity index, compaction characteristics, and California bearing ratio ( 0 percent, 10 percent, 20 percent, and 30 percent). The liquid limit and plastic limit continue to decrease when granite waste is added to black cotton soil, but the maximum wet density decreases and the dry density rises.

Jag Mohan Mishra et al (2014) the effect of Granite mud on the engineering properties of lime-stabilized black cotton soil was investigated. A study was done to determine the effect of granite mud on the engineering characteristics of $\mathrm{BC}$ soil stabilized with 5 percent lime and $0,10,20$, and $30 \%$ of granite mud. The soil was then prepared, and the compaction characteristic and California bearing ratio tests were carried out. The Proctor Compaction parameters have changed as a result of the lime stabilized B C Soil being combined with a completely new percentage of granite mud. The optimal wet content has been lowered, and the most dry density has been increased at the same time.

Eltwati et al (2020) The Engineering Properties of Clayey Soil Stabilized with Waste Granite Dust were investigated in detail. This study provides clayey soil stabilized with granite dust utilizing different percentages of granite dust, which are 4 percent, 8 percent, 16 percent, and 20 percent, respectively, as shown in the figure. There are several tests that are carried out. For the purpose of comparing the performance of the untreated and treated soils, CBR, compaction, and direct shear tests were conducted. The addition of granite dust significantly improved the shear strength, compressive strength, and dry density of the soil. According to the findings of this literature study, the addition of 8 percent granite dust to natural soil produces the most appropriate outcomes when compared to other contents of granite dust. It is determined that granite dust has excellent potential for application as an additive in the engineering of clayey soils, particularly in the construction of retaining walls.

Ogbonnaya et al (2011) the possible impact of granite dust on the geotechnical characteristics of Abakaliki clays was investigated. Granite dust with varied characteristics is used in this paper, with 10 percent, 15 percent, and 20 percent being used. There are several tests that are carried out, including Atterberg limits, standard compaction test, shear strength test, and California bearing ratio test. An Atterberg limit shows that an untreated sample of clay has a high liquid limit and a low plastic limit. When granite dust is added, the liquid limit is reduced, and the plastic limit is increased. The maximum dry density (MDD) varies between 1.93 and $1.68 \mathrm{mg} / \mathrm{m} 3$, and the CBR varies between 4-44 percent with the addition of 0-20 percent granite dust. Shear strength testing revealed an angle of shearing resistance ranging from 23.0-31.89 degrees and cohesiveness values ranging from 67.8-48.9 kpa. The results of the tests indicate that it may be utilized for a range of technical purposes.

Sai ganesh kumar at al (2015) studied the paper Subgrade strengthening of roads on black cotton soil using granite dust. Granite dust with varied characteristics is used in this paper with $10 \%, 20 \%$, $30 \%$ and $40 \%$ being used. The soil was then prepared, and the compaction characteristic and California bearing ratio tests were carried out. The Proctor Compaction parameters have changed as a result of the 


\section{SJIF Impact Factor 2021: 8.013| ISI I.F.Value:1.241| Journal DOI: 10.36713/epra2016 ISSN: 2455-7838(Online) EPRA International Journal of Research and Development (IJRD)}

lime stabilized B C Soil being combined with a completely new percentage of granite mud. The optimal wet content has been lowered, and the most dry density has been increased at the same time.

Uzma Rasool et al (2021) studied the stabilization of soil with glass (powder form) and granite dust for highways. Granite dust with varied characteristics is used in this paper $10 \%, 15 \%$, and $20 \%$ being used. The soil was then prepared, and the compaction characteristic and California bearing ratio tests were carried out. The Proctor Compaction parameters have changed as a result of the lime stabilized B C Soil being combined with a completely new percentage of granite mud. The optimal wet content has been lowered, and the most dry density has been increased at the same time.

\section{CONCLUSIONS}

Based on the results obtained and comparisons made in the present study, the following conclusions can be drawn:

- The optimum moisture content decreased with addition of calcium lingosulfonate and Granite dust separately

- The maximum dry density increased with addition of calcium lignosulfonate and Granite dust separately.

- $\quad$ Liquid limit, plastic limit goes on increasing by the addition of Calcium lignosulfonate to the clayey soil of varying percentages.

- Liquid limit, plastic limit goes on decreasing by the addition of Granite dust to the clayey soil of varying percentages.

- Many researches have studied the usage of Calcium lignosulfonate and Granite dust for soil stabilization. Therefore no researches are there combination of Calcium lignosulfonate and Granite dust and we have studied in this paper.

\section{REFERENCES}

1. Chavali, $R$. and Reshmarani, B., 2020. Characterization of expansive soils treated with lignosulfonate. International Journal of GeoEngineering, 11(1).

2. Alazigha, D., Indraratna, B., Vinod, J. and Ezeajugh, L., 2016. The swelling behaviour of lignosulfonate-treated expansive soil. Proceedings of the Institution of Civil Engineers - Ground Improvement, 169(3), pp.182-193.

3. Alazigha, D., Indraratna, B., Vinod, J. and Heitor, A., 2018. Mechanisms of stabilization of expansive soil with lignosulfonate admixture. Transportation Geotechnics, 14, pp.81-92.
4. $a u, R ., \quad b j, \quad P$. and $k, J .$, 2017. Experimental Investigation of Lateritic Soil treated with Calcium Lignosulfonate. Indian Geotechnical Conference, pp.14-16.

5. BS, S. and y, S., 2018. Stabilization of Kuttanad soil using Calcium and Sodium Lignin Compounds. International Journal for Research in Applied Science and Engineering Technology, 6(2), pp.580-586.

6. Fernández, M., Orlandi, S., Codevilla, M., Piqué, T. and Manzanal, D., 2021. Performance of calcium lignosulfonate as a stabiliser of highly expansive clay. Transportation Geotechnics, 27, p.100469.

7. Ijaz, N., Dai, F., Meng, L., Rehman, Z. and Zhang, H., 2020. Integrating lignosulphonate and hydrated lime for the amelioration of expansive soil: A sustainable waste solution. Journal of Cleaner Production, 254, p.119985.

8. Ta'negonbadi, B. and Noorzad, R., 2018. Physical and geotechnical long-term properties of lignosulfonate-stabilized clay: An experimental investigation. Transportation Geotechnics, 17, pp.41-50.

9. v, G. and s, A., 2019. Stabilization of clayey soil using lignosulfonate. International Research Journal of Engineering and Technology, 6(2), pp.1963-1967.

10. Vakili, A., Ghasemi, J., bin Selamat, M., Salimi, M. and Farhadi, M., 2018. Internal erosional behaviour of dispersive clay stabilized with lignosulfonate and reinforced with polypropylene fiber. Construction and Building Materials, 193, pp.405-415.

11. Vakili, A., Kaedi, M., Mokhberi, M., Selamat, M. and Salimi, M., 2018. Treatment of highly dispersive clay by lignosulfonate addition and electroosmosis application. Applied Clay Science, 152, pp.1-8.

12. vijayan, G. and Sasikumar, A., 2019. Effect of Lignosulfonate on Compaction and Strength Characteristics of Clayey Soil. International Journal of Research in Engineering, Science and Management, 2(4), pp.634 - 636.

13. Thirumalai, r., Suresh Babu, S., Naveennayak, v., Ragavendra, b. and Praveenkumar, g., 2020. Stabilization of Black Cotton Soil by using Quarry Dust and granite waste. International Research Journal of Engineering and Technology, 4(8), pp.226-229.

14. Zorluer, I. and GÜCEK*, S., 2017. Usage of Fly Ash and Granite Dust for Soil Stabilization. Periodicals of Engineering and Natural Sciences (PEN), 5(1), pp.533-538.

15. Preethi, A., Mahesh, M., Prem kumar, N., Vinay kumar, C. and Murali mohan, N., 2018. Stabilization of black cotton soil using granite waste. International Journal of Technical Innovation in Modern, 4(4), pp.40-45. 


\section{EPRA International Journal of Research and Development (IJRD)}

Volume: 6 | Issue: 9 | September 2021

- Peer Reviewed Journal

16. Mishra, J., Yadav, R. and Singhai, A., 2014. Effect of Granite Dust on Engineering Properties of Lime Stabilized Black Cotton Soil. International Journal of Engineering Research \& Technology, 3(1), pp.832-837.

17. Ogbonnaya, I. and Illoabachie, D., 2011. The potential effect of granite dust on the geotechnical properties of abakaliki clays. Continental J. Earth Sciences, (1), pp.23-30.

18. Salman Eltwati, A., Tarhuni, F. and Elkaseh, A., 2020. Engineering properties of clayey soil stabilized with waste granite dust. International Journal of Advanced Science and Technology, 29(10), pp.750-757.

19. Uzma, R., Neeraj, K., 2021 Stabilization of soil with glass (powder form) and marble dust for highwaysreview International Journal of Advanced Science and Technology, 8(3), pp.2395-0056.

20. Sai ganesh kumar, P., Sai sumedha, $R$. and Pradeep, U., 2015.Subgrade strengthening of roads on black cotton soil using granite dust International Journal of Engineering Research \& Technology, 4(6), pp.2321-7308. 